\title{
MONITORAMENTO DA COBERTURA VEGETAL ATRAVÉS DE ÍNDICES BIOFÍSICOS E GESTÃO DE ÁREAS PROTEGIDAS
}

\author{
Alexsandro Bezerra Correia Bilar ${ }^{1}$ \\ Rejane Magalhães de Mendonça Pimentel ${ }^{2}$ \\ Michelle Adelino Cerqueira ${ }^{3}$
}

\begin{abstract}
Resumo: A manutenção da diversidade da vegetação estabelecida em áreas de caatinga encontra-se sob grande risco e a criação de áreas protegidas é uma estratégia vital para a sua preservação. A utilização de sensoriamento remoto e a aplicação de índices de vegetação contribuirão para uma maior eficiência no seu monitoramento, o que não é uma prática comum no Brasil. O estudo objetivou identificar a condição da cobertura vegetal de uma unidade de conservação da natureza, através da aplicação de índices biofísicos: NDVI, LAI, SAVI, EVI e NDWI, gerados a partir da análise de imagens orbitais referentes aos anos de 2007, 2013 e 2016. Constatou-se que a cobertura vegetal dessa unidade de conservação se encontra relativamente preservada, com a detecção das áreas expostas e sob estresse hídrico, informações indispensáveis para a gestão de espaços legalmente protegidos.
\end{abstract}

Palavras-chave: Caatinga; Planejamento ambiental; Sensoriamento remoto

\section{MONITORING OF VEGETATION COVER THROUGH BIOPHYSICAL INDICES AND MANAGEMENT OF PROTECTED AREAS}

\begin{abstract}
The maintenance of vegetation diversity established in caatinga areas is at great risk, and the creation of protected areas is a vital strategy for their preservation. The use of remote sensing and the application of vegetation indices will contribute to greater efficiency in its monitoring, which is not a common practice in Brazil. The objective of this study was to identify the condition of the vegetation cover of a nature conservation unit, through the application of biophysical indexes: NDVI, LAI, SAVI, EVI and NDWI, generated from the analysis of orbital images for the years 2007, 2013 and 2016. It was verified that the vegetation cover of this protected area is relatively preserved, with the detection of exposed areas and under water stress, indispensable information for the management of legally protected spaces.
\end{abstract}

Keywords: Caatinga; Environmental planning; Remote sensing

\footnotetext{
${ }^{1}$ Doutorando do Programa de Pós-Graduação em Desenvolvimento e Meio Ambiente da Universidade Federal de Pernambuco (PRODEMA/UFPE) e Professor Assistente da Unidade Acadêmica de Serra Talhada da Universidade Federal Rural de Pernambuco (UAST/UFRPE). Email: alexsandrobilar@yahoo.com.br

2 Professora do Departamento de Biologia, área Botânica da Universidade Federal Rural de Pernambuco (UFRPE). Possui Doutorado em Botânica pela UFRPE e Pós-doutoramento pela School of Environmental Sciences, University of Guelph, Canadá. Email: rejanemmpimentel@gmail.com

${ }^{3}$ Professora Assistente da Unidade Acadêmica de Serra Talhada da Universidade Federal Rural de Pernambuco (UAST/UFRPE).Email: adelino@gmail.com
} 


\section{MONITOREO DE LA COBERTURA VEGETAL A TRAVÉS DE ÍNDICES BIOFÍSICOS Y DE LA GESTIÓN DE ÁREAS PROTEGIDAS}

Resumen: El mantenimiento de la diversidad de la vegetación en áreas de caatinga se encuentra bajo gran riesgo y la creación de áreas protegidas es una estrategia vital para su preservación. El uso de detección remota y la aplicación de índices de vegetación contribuirá a una mayor eficiencia en su control, que no es una práctica común en Brasil. El estudio pretende identificar la condición de la cubertura vegetal de una unidad de conservación de la naturaleza, mediante la aplicación de índices biofísicos: NDVI, LAI, SAVI y NDWI, generados a partir del análisis de imágenes orbitales de los años 2007, 2013 y 2016. Se constató que la cubertura vegetal de esta unidad de conservación se encuentra relativamente preservada con la detección de áreas expuestas y bajo estrés hídrico, informaciones esenciales para la gestión de espacios legalmente protegidos.

Palabras clave: Caatinga; Planificación del medio ambiente; Detección remota

\section{INTRODUÇÃO}

A vegetação de caatinga apresenta grande biodiversidade, onde ocorrem 318 espécies endêmicas, com destaque para a família Leguminosae (Fabaceae) e uma reconhecida capacidade de se ajustar às adversidades ambientais, com mecanismos de florescimento e frutificação diferenciados, além da queda de folhas durante a estação seca (caducifolia), garantindo sua sobrevivência frente à escassez hídrica (CARRIÓN et al., 2017; GIULIETTI et al., 2004; LEAL, TABARELLI e SILVA, 2003; LIMA, 2010; LIMA et al., 2013; QUEIROZ, 2002; SILVA, 2012;).

Apesar dessa incontestável riqueza vegetal, é comprovado um elevado grau de vulnerabilidade em muitas das espécies estabelecidas na caatinga (CHAGAS, 2012; SILVA et al., 2008). Além de constituir um bioma característico de uma região semiárida, sob grave degradação há décadas, por incessantes e inconsequentes atividades antrópicas, aproximadamente metade de sua cobertura vegetal original e muitas de suas espécies estão sob sério risco de extinção (BRASIL, 2017; FERREIRA, 2013; NOBRE, 2011).

Dentre as principais características dessa vegetação, destacam-se a acentuada queda foliar, que ocorre, anualmente, durante a estação seca (RODAL e SAMPAIO, 2002), e o desenvolvimento de diferentes estratégias de dispersão de sementes e armazenamento de água (LIMA, 2010). A precipitação é um fator preponderante na regulação do comportamento fenológico da maioria das espécies (AMORIM; SAMPAIO e ARAÚJO, 2009; LIMA, 2010).

Uma das principais medidas implementadas, em todo o mundo, para a preservação de florestas e sua biodiversidade é a criação de áreas protegidas (BENSUSAN, 2006; PINTO, 2008). Porém, a simples existência desses espaços, legalmente instituídos, não garante que 
seus propósitos preservacionistas sejam efetivamente alcançados, fazendo-se necessárias outras ações governamentais, como atividades de educação ambiental, visando minorar os impactos negativos decorrentes do uso inadequado do solo, assim como a gestão dessas áreas, incluindo o monitoramento constante da condição de sua cobertura vegetal. Estas ações vêm sendo facilitadas com a utilização de imagens orbitais, captadas por sensores instalados em satélites, os quais, graças ao crescente avanço tecnológico, aumentam, continuamente, sua capacidade de resolução (espectral, espacial e temporal), permitindo a detecção de desmatamentos, queimadas e áreas sob riscos de desertificação, assim como o acompanhamento dos usos do solo e dos impactos ambientais causados pelas atividades humanas, subsidiando a tomada de decisões para a preservação ambiental (FLORENZANO, 2007; MENESES, 2012; MOREIRA, 2003; NOVO, 2008; RODRIGUES et al., 2009; SEIFFERT, 2010; WENG, 2010).

Recursos tecnológicos, como o sensoriamento remoto, auxiliam, eficientemente, os gestores governamentais durante o processo decisório, pois, além das vantagens, também possibilitam: a projeção de cenários, a obtenção de informações à distância e, algumas vezes, em tempo real, maior efetividade no planejamento, na execução e no controle de estratégias preservacionistas e de recuperação de áreas degradadas, além de servirem como base para a elaboração de novas políticas públicas ambientais e de novos instrumentos para monitorar a natureza (CURI, 2011; GOMES, GOMES e ALMEIDA, 2009; SEIFFERT, 2010; SHIMIZU, 2006).

A utilização do sensoriamento remoto e a aplicação conjunta de índices de vegetação, também chamados índices biofísicos, apresentam-se como instrumentos eficientes e eficazes para avaliar e monitorar as condições da cobertura vegetal de uma região geográfica, em função de sua precisão, praticidade e caráter multiespectral (CHAGAS, 2012; RIBEIRO et al., 2016; SALLO et al., 2014). Dentre os índices que, tradicionalmente, são adotados para essa análise temos o índice de vegetação por diferença normalizada ou Normalized Difference Vegetation Index (NDVI), proposto por Rouse et al., (1973), muito utilizado na avaliação da espacialização e da evolução da cobertura vegetal; o índice de vegetação ajustado ao solo ou Soil-Adjusted Vegetation Index (SAVI), desenvolvido por Huete (1988), permitindo minimizar a influência da reflectância dos solos claros ou escuros em meio à vegetação (efeito background); o índice de umidade por diferença normalizada ou Normalized Difference Water Index (NDWI), elaborado por Gao (1996), relacionado ao levantamento de escassez hídrica; o índice de vegetação otimizado ou Enhanced Vegetation Index (EVI), elaborado por Huete et 
al. (1997), adotado como fator de ajuste para aprimorar o sinal das plantas e o índice de área foliar ou Leaf Area Index (LAI), apresentado por Allen et al. (2002), utilizado para a determinação da biomassa.

Estes índices auxiliam no entendimento da dinâmica da vegetação, avaliando caracteres como a densidade, o vigor, a variação sazonal e a distribuição no solo (CHAGAS, 2012; TEIXEIRA, 2003), informações de grande relevância para uma maior eficiência na gestão das unidades de conservação da natureza (OLIVEIRA, 2013).

Considerando o caso específico da vegetação de caatinga, merecem destaque os índices: NDVI, muito adotado em regiões semiáridas por destacar e caracterizar a cobertura vegetal, SAVI, capaz de minimizar a reflectância do solo (background), principalmente durante o período seco do ano, e NDWI, por avaliar a umidade do solo. Tais índices são muito utilizados pesquisassem estudos relacionados às temáticas envolvendo monitoramento ambiental, desertificação e avaliação de corpos hídricos (rios e bacias hidrográficas) (BARBOSA; HUETI; BAETHGEN, 2006; BEZERRA, SILVA e BEZERRA, 2011; GALVÍNCIO et al., 2016; GURGEL; FERRERIA; LUIZ, 2003; RODRIGUES et al., 2009; SILVA; GALVÍNCIO, 2012).

As informações geradas a partir do uso desses parâmetros são essenciais para subsidiar o planejamento e gestão de recursos naturais (BEZERRA et al., 2014), especialmente em áreas legalmente protegidas. Rodriguez, Silva e Cavalcanti (2013) afirmam que o planejamento ambiental do território é um elemento indispensável para a confecção e posterior acompanhamento de programas de desenvolvimento local sustentável, planos uso, de manejo e processos de gestão de uma unidade de paisagem.

Dados obtidos por sensoriamento remoto e ferramentas digitais, como o Sistema de Informações Geográficas - SIG e a classificação territorial em Unidades de Paisagem Natural - UPN, são muito utilizados para o zoneamento e a elaboração dos planos de manejo das unidades de conservação brasileiras, com uma abordagem relacionada ao uso, tanto da vegetação quanto do solo (ELAP, 2015).

A aplicação de índices de vegetação ainda não faz parte da rotina envolvendo a gestão de espaços destinados à preservação da natureza, seja pela ausência de conhecimento, capacitação técnica e articulação institucional ou, até mesmo, pelo interesse dos órgãos públicos ambientais. Merece destaque a proposta de utilização de índices de vegetação na gestão do Parque Estadual Mata da Pimenteira (PEMP), criado no ano de 2012, em Serra Talhada, pelo Governo do Estado de Pernambuco e gerido pela Agência Pernambucana de 
Meio Ambiente (CPRH) (PERNAMBUCO, 2012).

O plano de manejo desse parque foi elaborado no ano de 2013 com a utilização de imagens de satélite para a caracterização e o zoneamento da sua área (PERNAMBUCO, 2013), entretanto, sem o complemento de índices biofísicos e a definição de indicadores da condição de conservação desejada para essa área legalmente protegida.

Este estudo visa identificar a condição da cobertura vegetal do PEMP utilizando os índices de vegetação NDVI, LAI, SAVI, EVI e NDWI, para auxiliar no monitoramento ambiental e tomada de decisões relacionadas à gestão dessa unidade de conservação integral.

\section{MATERIAL E MÉTODOS}

\section{Área de estudo}

O Parque Estadual Mata da Pimenteira (PEMP) (Figura 1) foi criado pelo Decreto Estadual $n^{\circ} 37.823$, de janeiro de 2012, em uma área com 887,24 ha, com uma zona de amortecimento (ZA) (área delimitada no seu entorno para minimizar impactos negativos externos) com 6847,17 ha, localizada nos extremos geográficos entre 753’21” e 757’36” S e 38¹8’42" e 38 $17^{\prime} 17^{\prime}$ W. Está localizado na Fazenda Saco, na mesorregião Sertão Pernambucano, microrregião do Pajeú, no município de Serra Talhada/PE, com uma área de $2.980 \mathrm{~km}^{2}$, densidade demográfica de $26,59 \mathrm{hab} / \mathrm{km}^{2}$, população estimada em 85.568 habitantes e distante $415 \mathrm{~km}$ da capital do estado de Pernambuco, a cidade do Recife (IBGE, 2017; PERNAMBUCO, 2012 e 2013).

A cobertura vegetal é caracterizada por fragmentos de vegetação arbustivo-arbórea, do tipo caatinga hiperxerófila com trechos de floresta caducifólia (PERNAMBUCO, 2013). 


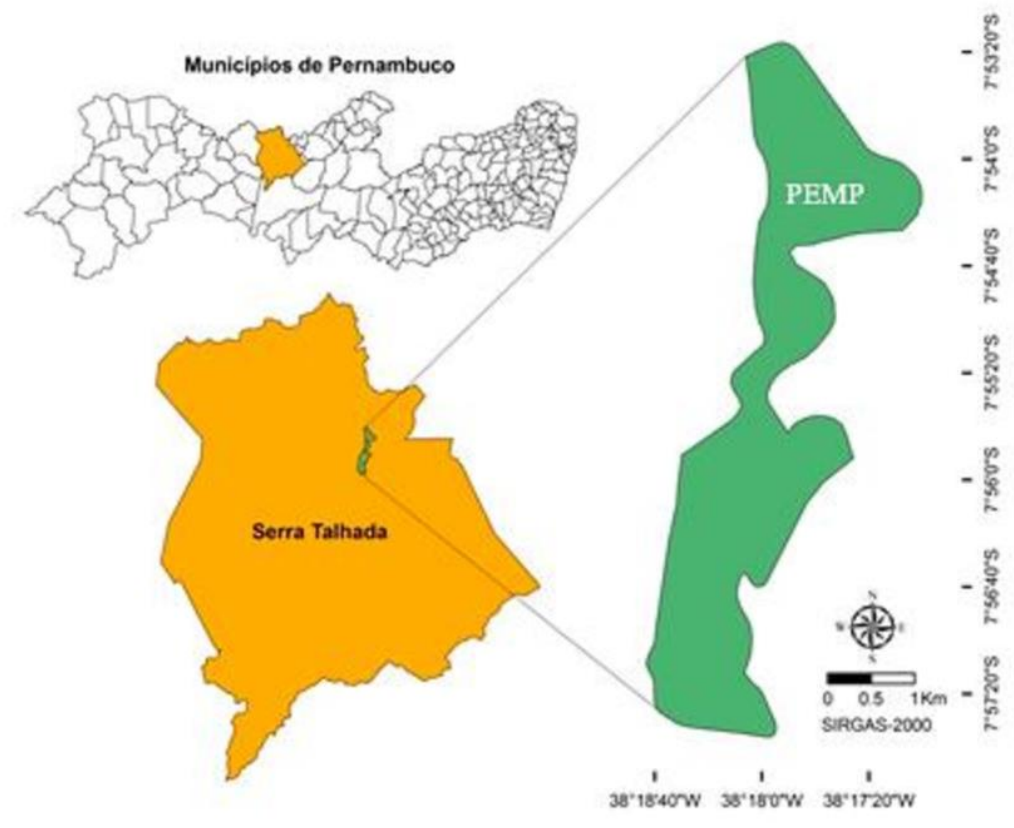

Figura 1 - Localização do Parque Estadual Mata da Pimenteira (PEMP) no município de Serra Talhada/PE. Fonte: Bilar (2016).

A lista florística das espécies registradas na área de caatinga do PEMP, presente em seu plano de manejo, conforme levantamentos realizados por Farias (2013), Ferraz et al. (1998) e Menezes (2009), compreende 130 espécies herbáceas e 75 lenhosas típicas da caatinga, destacando-se a família Leguminosae, com 33 espécies (MATOS, MELO e SILVA, 2016), dentre as quais: a imburana-de-cheiro (Amburana cearenses) e o angico (Anadenanthera colubrina), além da família Anacardiaceae, cujas espécies aroeira (Myracrodruon urundeuva) e baraúna (Schinopsis brasiliensis) foram recentemente citadas na relação de espécies ameaçadas de extinção do Ministério do Meio Ambiente (PERNAMBUCO, 2013).

De acordo com estudo climatológico relativo a essa unidade de conservação, realizado por Silva e Almeida (2013), o PEMP apresenta clima do tipo BSwh, segundo Köppen, temperatura média anual em torno de $24^{\circ} \mathrm{C}$, umidade relativa do ar média de $64 \%$ e precipitação mais significativa a partir de dezembro até maio, sendo os meses de janeiro a abril os mais chuvosos, totalizando uma média anual de quase $650 \mathrm{~mm}$, além de uma elevada demanda atmosférica, ou evapotranspiração potencial, em torno de 1350mm/ano, principalmente entre outubro e abril, o que significa reduzida disponibilidade hídrica para a vegetação, especialmente enfatizada pela predominância de solos litólicos (rasos), em associação com podzólicos vermelho-amarelo, e afloramentos rochosos.

A área de proteção ambiental em estudo, pertencente ao grupo proteção integral, possui características climáticas típicas do semiárido nordestino, como médias anuais de precipitação 
inferiores a 800mm e elevada evapotranspiração (BRASIL, 2000; MOURA et al., 2007).

Na zona de amortecimento do PEMP estão estabelecidas comunidades rurais: Mocambo e Laginha, a noroeste; Carnaúba do Ajudante, a oeste; Boi Morto, Xique-Xique e Ivan Souto de Oliveira, a nordeste; comunidade da Fazenda Saco (IPA), ao leste. Há décadas, as populações dessas localidades desenvolvem atividades agropecuárias, sobretudo agricultura de subsistência, às margens do córrego Luanda (a oeste).

\section{Procedimentos para coleta e análise dos dados}

Neste estudo foram utilizadas seis imagens orbitais captadas pelos sensores Thematic Mapper (TM) do satélite Landsat 5 e Operational Land Imager (OLI) do satélite Landsat 8, com resolução espacial de 30x30 metros e resolução temporal de 16 dias, com órbita/ponto 216/065, referentes às datas de passagem 26/07/2007, 28/09/2007, 24/06/2013, 28/09/2013, 03/08/2016 e 20/09/16, respectivamente, obtidas gratuitamente através do site: http://glovis.usgs.gov.

Realizou-se um levantamento pluviométrico mensal, do período de 1958 a 2016, através de dados obtidos junto ao Posto 12 do Instituto Agronômico de Pernambuco (IPA), em Serra Talhada, disponíveis no site da Agência Pernambucana de Águas e Clima (APAC).

As ocorrências dos eventos El Niño e La Niña foram consideradas com base na metodologia adotada pela National Oceanic and Atmospheric Administration, pois, segundo Molion e Bernardo (2002), esses fenômenos climáticos influenciam, fortemente, o clima do Nordeste do Brasil; anos com chuvas abaixo da média estão associados a eventos de El Niño intensos, enquanto em anos chuvosos estão relacionados a intensidade de eventos La Niña.

Para a visualização e realização das operações matemáticas utilizou-se o software ERDAS 9.3, mediante licença do Laboratório de Sensoriamento Remoto e Geoprocessamento do Departamento de Ciências Geográficas da Universidade Federal de Pernambuco (SERGEO/DCG/UFPE).

\section{Índices de vegetação}

Para avaliar a condição da vegetação foram calculados os índices: NDVI (índice de vegetação por diferença normalizada), NDWI (índice de umidade por diferença normalizada), SAVI (índice de vegetação ajustado ao solo), EVI (índice de vegetação otimizado) e LAI (índice de área foliar).

Inicialmente, a reflectância foi calculada através da Equação 1, desenvolvida por Allen 
et al. (2002), para as imagens do satélite Landsat 5:

$$
\rho \lambda \mathrm{i}=\frac{\pi \cdot L A i}{K \lambda i \cdot \cos Z \cdot d r} \quad \text { Eq. (1) }
$$

onde: $\mathrm{L} \lambda \mathrm{i}$ é a radiância espectral de cada banda, $\mathrm{K} \lambda \mathrm{i}$ é a irradiância solar espectral de cada banda no topo da atmosfera, $\mathrm{Z}$ é o ângulo zenital solar e dr é o quadrado da razão entre a distância média Terra-Sol (ro) e a distância Terra-Sol (r) em dado dia do ano (DSA).

A Equação 2 foi utilizada para as imagens do satélite Landsat 8:

$$
P \lambda^{\prime}=\frac{\mu \rho X Q \operatorname{Qsa} X A \rho}{\sin (\theta S e)} \quad \text { Eq. (2) }
$$

onde: $\mathrm{P} \lambda \lambda^{\prime}$ é a reflectância; $\mu \rho$ é reflectância multi_banda_x; Ap é reflectância_Add_banda $\mathrm{X} ; \sin \left({ }^{\theta S e}\right)$ é a elevação do sol; e Qca é o número digital da imagem.

O NDVI, proposto por Rouse et al. (1973), foi utilizado para identificar a distribuição e o desenvolvimento da vegetação, onde os valores variam entre -1 e +1 . Os valores negativos correspondem aos corpos hídricos e os positivos informam sobre a exuberância da vegetação verde na superfície e elevada quantidade de biomassa, sendo determinado pela Equação 3:

$$
N D V I=\frac{\text { pnir }- \text { pred }}{\text { pnirt pred }} \quad \text { Eq.(3) }
$$

onde: $\rho$ nir é o fluxo radiante refletido no infravermelho próximo, representado pela banda 4 do sensor TM, do satélite Landast 5, e pela banda 5, do sensor OLI, do satélite Landsat 8, respectivamente, e pred é o fluxo radiante refletido no vermelho da região do visível, representado pela banda 3, do sensor TM, do satélite Landsat 5 e pela banda 4, do sensor OLI, do satélite Landsat 8, respectivamente.

O NDWI foi calculado para monitorar o estresse hídrico, comum no semiárido, e por ter menor sensibilidade a efeitos atmosféricos (OLIVEIRA et al., 2010). Sua equação foi proposta por Gao (1996):

$$
N D W I=\frac{\text { pnir }- \text { pmidir }}{\text { pnir }+ \text { pmidir }} \quad \text { Eq.(4) }
$$

onde: pmidir é o fluxo radiante refletido no infravermelho médio, representado pela banda 5, do sensor TM, do satélite Landsat 5 e pela banda 6, do sensor OLI, do satélite Landsat 8.

Quanto maior a presença de água no ambiente, maior será o valor do NDWI.

O SAVI foi aplicado para atenuar os efeitos do background no solo, em função da resposta espectral da vegetação, utilizando a Equação 5, proposta por Huete (1988):

$$
\text { SAVI }=(1+L) \frac{\text { pnir- } \rho_{\text {red }}}{L+\text { pnirt }+ \text { pred }} \quad \text { Eq. (5) }
$$

onde: L é um fator de ajuste, e pode assumir valores de 0,25 (vegetação densa); 0,5 (vegetação com densidade intermediária) e 1 (vegetação com baixa densidade). Este estudo 
utilizou o valor de $\mathrm{L}=0,5$.

Esse índice varia de $-1,5$ a 1,5, sendo que o valor positivo significa áreas com presença de vegetação e em áreas expostas, corpos hídricos e nuvens o valor geralmente é negativo.

O índice de vegetação otimizado (EVI) proposto por Huete et al. (1997) foi escolhido porque otimiza o sinal da vegetação intensificando a resposta em áreas com grandes concentrações de biomassa e reduz interferências do solo e atmosféricas (RODRIGUES et al., 2013). Foi calculado pela Equação 6:

$$
E V I=G \frac{\rho_{\text {nir }}-\rho_{\text {red }}}{\rho_{\text {nir }}+C_{1} \cdot \rho_{\text {nir }}-C_{\text {n. }} \cdot \rho_{\text {blue }}+L} \text { Eq.(6) }
$$

onde: $\mathrm{G}$ é o fator de ganho cujo valor utilizado é 2,5; L=1 é o fator de ajuste do background; $\mathrm{C}_{1}$ $=6$ e $\mathrm{C}_{2}=7,5$ são os coeficientes de correção para atenuar os efeitos dos aerossóis nas faixas do azul e vermelho do espectro eletromagnético.

O índice de área foliar (LAI) foi aplicado para indicar a biomassa de cada pixel da imagem, através da razão entre a área foliar de toda a vegetação por unidade de área utilizada por essa vegetação, segundo Equação 7, proposta por Allen et al. (2002):

$$
L A I=\frac{\operatorname{Ln}\left(\frac{0,69-\text { SAVI }}{0,59}\right)}{0,91} \text { Eq. (7) }
$$

\section{RESULTADOS}

\section{Levantamento pluviométrico}

Os resultados revelaram a ocorrência de uma considerável variabilidade pluviométrica interanual no mês de fevereiro dos anos imageados, quando comparados à média dos 55 anos. Entretanto, o comportamento apresentado pelas precipitações, a partir de abril, para o ano de 2013, e para maio, observando os anos de 2007 e 2016, aproximou-se da média histórica pesquisada, com exceção do mês de dezembro, considerando esses três anos.

A Figura 2 mostra o levantamento dos dados pluviométricos mensais do Posto 12 IPA, Serra Talhada-PE, para os anos 2007, 2013 e 2016, e a média de 55 anos, de 1958 a 2016 , excetuando-se os anos 1979, 1992 e 1993, para os quais não constam registros no site da APAC. 


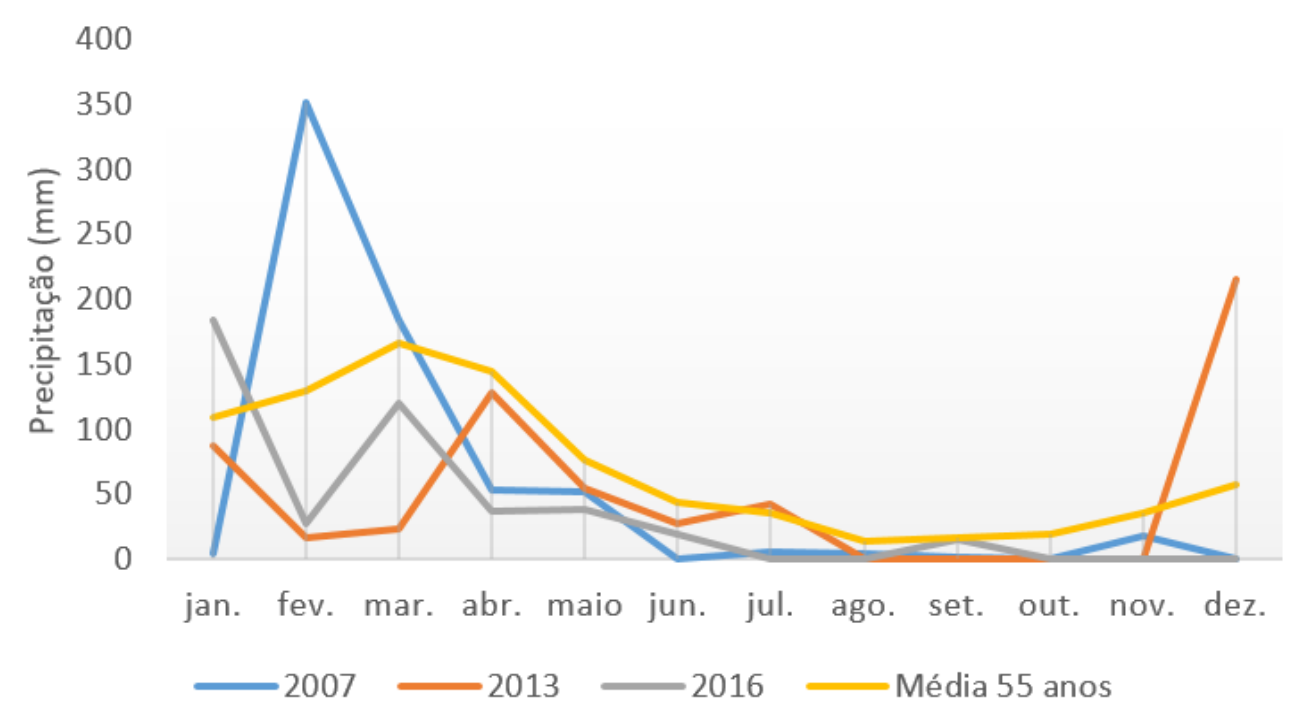

Figura 2 - Balanço mensal de precipitação para os anos imageados e média de 55 anos. Fonte: Bilar (2017).

O total anual de precipitações, de acordo com dados levantados na APAC, foi de 678 mm em 2007, 598,3 mm em 2013 e de 443,6 mm em 2016. A média calculada para os 55 anos foi de $788 \mathrm{~mm}$.

Segundo a National Oceanic and Atmospheric Administration - NOAA, em 2007 houve influência do evento La Niña, em 2013 não foram registradas influências muito fortes dos fenômenos El Niño e La Niña e, em 2016, ocorreu o evento El Niño.

A Figura 3 mostra a dispersão dos dados pluviométricos diários do início dos anos estudados até as três últimas datas imageadas: 28/09/2007, 28/09/2013 e 20/09/2016. 


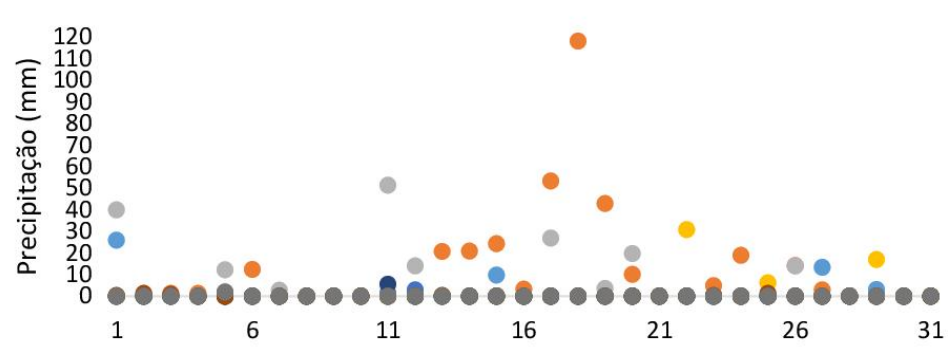

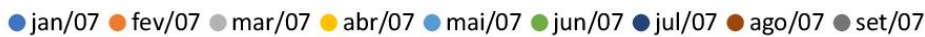

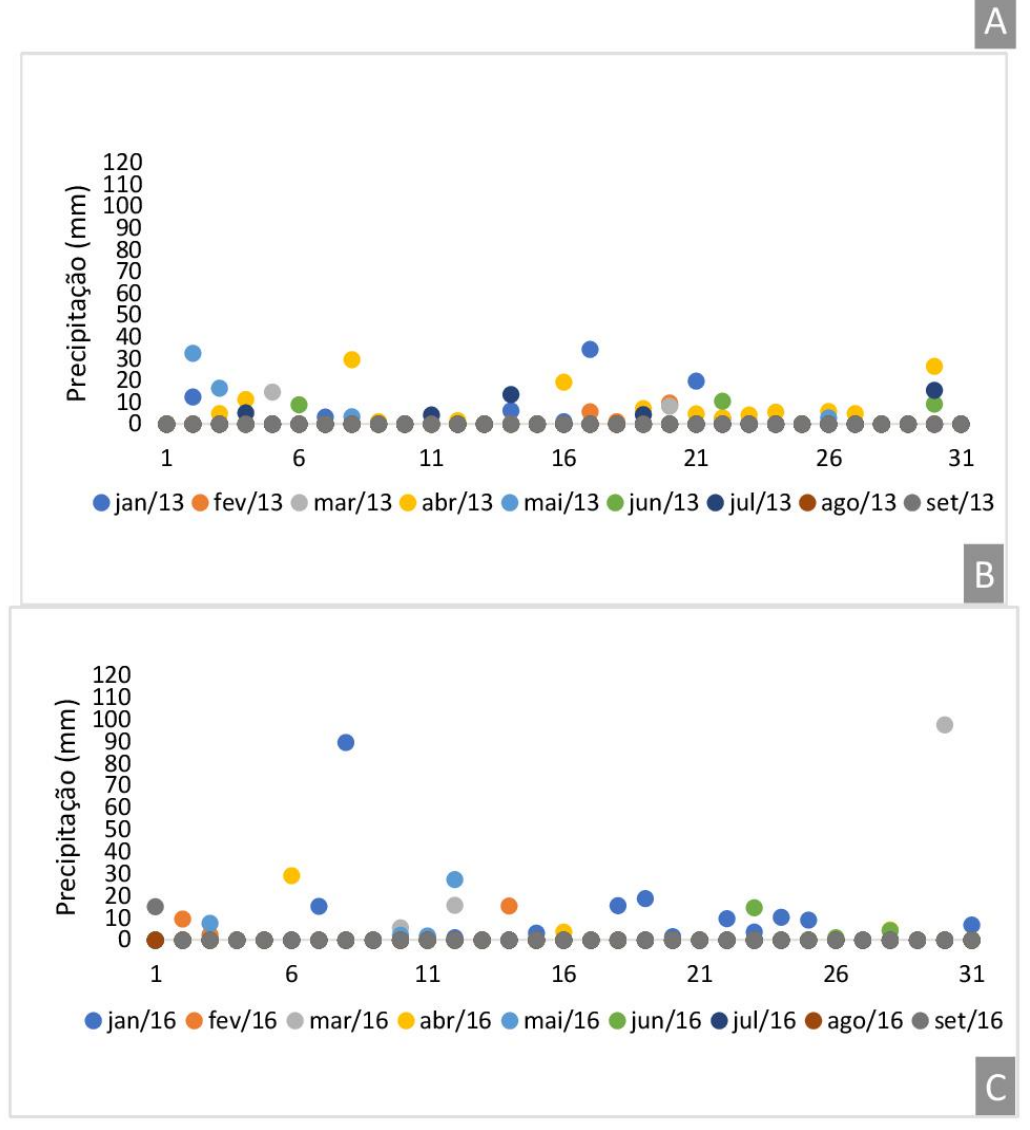

Figura 3 - Dispersão dos dados pluviométricos diários em: A. 2007, B. 2013 e C. 2016. Fonte: Bilar (2018).

Considerando a série histórica pesquisada, o período mais chuvoso do ano, na área estudada, ocorreu durante os meses de janeiro a abril e o mais seco, de agosto a outubro.

Dentre os três anos pesquisados, 2007 foi o que apresentou maior variação dos dados pluviométricos diários. Nos dias 17 e 18 de fevereiro foi registrada uma precipitação acumulada de 171,6 mm, enquanto apenas 9,9 $\mathrm{mm}$ foram computados para o acumulado dos meses de junho, julho e agosto. O último registro de precipitação, antes do dia 26/7/2007, data da primeira imagem orbital escolhida para o estudo, ocorreu em 11/07/2007 (5,6 mm). No dia 05/09/2007 ocorreu o último registro de precipitação $(2 \mathrm{~mm}$ ) antes de 28/09/2007, data da segunda imagem orbital. 
Em 2013 ocorreu uma maior regularidade na distribuição da precipitação e o maior patamar registrado foi para o dia 17 de janeiro (34,2 mm). Em 22/06/2013, dois dias antes do registro da terceira imagem orbital, foram registrados 10,4 mm e, em 08/06/2013, 8,8 mm. Nos meses de agosto e setembro não ocorreu precipitação.

Não houve registro de precipitação em julho e agosto de 2016. As datas de passagem do satélite escolhidas neste estudo, para esse mesmo ano, foram 03/08 e 20/09. Em 01/09/2016, 19 dias antes dessa última imagem orbital, a precipitação registrada foi de 15,2 mm.

\section{Índices de vegetação}

Os resultados < 0 para os índices NDVI, LAI, SAVI e EVI e > 0,32 para o NDWI, simulados pela tonalidade azul para as três datas analisadas (Figura 4), representam os corpos hídricos, referentes aos açudes do Saco I e Cachoeira II, localizados nas porções leste e sudoeste da zona de amortecimento (ZA) do Parque Estadual Mata da Pimenteira (PEMP), respectivamente.

A Figura 4 mostra um quadro comparativo com os resultados calculados para os índices NDVI, LAI, SAVI, EVI e NDWI, a partir das imagens orbitais do PEMP referentes às seguintes datas de passagem dos satélites Landsat 5 e 8, respectivamente: 26/07/2007, 24/06/2013 e 03/08/2016. 


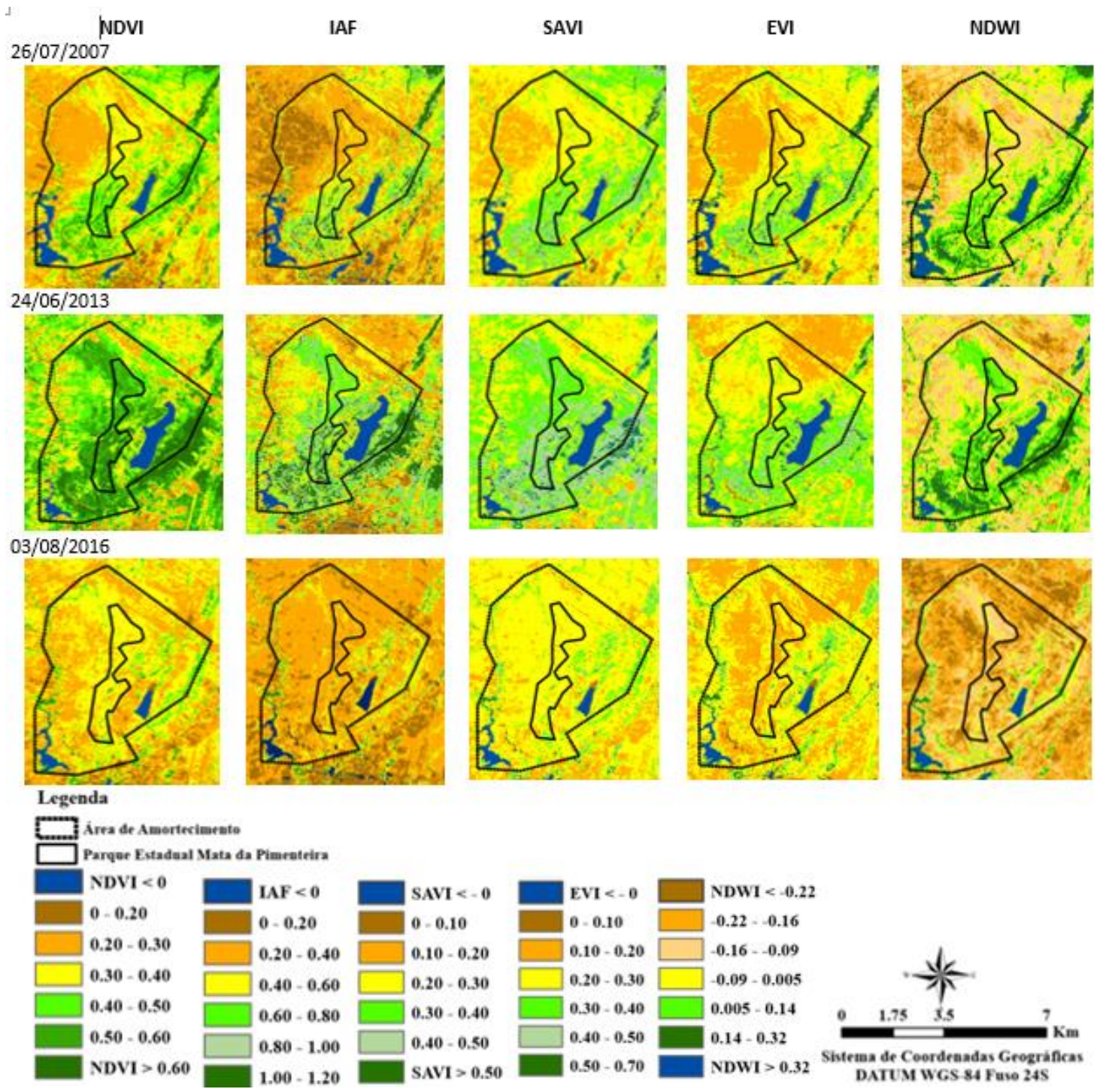

Figura 4 - Comparativo índices de vegetação do Parque Estadual Mata da Pimenteira (PEMP) para as datas: 07/2007, 06/2013 e 08/2016. Fonte: Bilar e Cerqueira (2017).

Para a imagem do dia 26/07/2007, os cálculos apontaram valores de NDVI > 0,40 e SAVI > 0,30 (cor verde-claro) em cerca de 45\% da área do PEMP, principalmente em sua porção sul, indicando a presença de vegetação verde, apesar da perda de folhas (caducifolia) em determinada época do ano, particularmente no período mais seco do ano, nesta região do estado de Pernambuco. Os valores positivos obtidos pelo NDWI, simulados pelas tonalidades verdes, indicam a presença de umidade nessa área. O LAI $<0,20$, simulado pela cor marrom, identificado na porção noroeste da zona de amortecimento do parque, representa ausência foliar. Esse fato, somado aos valores encontrados para o EVI $(<0,20)$ e o NDWI $(<-0,016)$, indicam se tratar da área da ZA com maior patamar de estresse hídrico.

Analisando-se a imagem do dia 24/06/2013, logo após o enceramento do período chuvoso, constatou-se, ao contrário da imagem de 2007, que o PEMP apresentava 
considerável vigor vegetativo, com NDVI > 0,50, LAI > 0,60 e valores positivos de NDWI, simulados na Figura 4 pelas tonalidades de cor verde, abrangendo praticamente toda a área da unidade de conservação. Merecem destaque os valores de NDVI e LAI inferiores a 0,20, identificados nas áreas próximas à ZA do PEMP, ao sul e sudeste, simulados pela cor marrom. Nessas áreas estão presentes edificações e terrenos com solos expostos de bairros da periferia da cidade de Serra Talhada (José Tomé de Souza Ramos, CAGEP e Bomba), situados às margens da BR 232 e da PE 365.

Em relação à imagem do dia 03/08/2016, no começo do período mais seco do ano para a região, os resultados dos índices NDVI < 0,40 e SAVI < 0,30, simulados pela tonalidade de cor amarelo, em mais de $95 \%$ da área do parque, indicaram grande estresse hídrico, ausência de folhas (caducifolia) e solo exposto. Chamou atenção para esse período a considerável redução do espelho d'água do Açude do Saco I, na porção leste da ZA do PEMP. Valores positivos para o NDWI foram detectados apenas em pontos isolados do parque e nos cursos e reservatórios de água presentes em sua zona de amortecimento. Valores de SAVI e EVI superiores a 0,30 foram raros, registrados, principalmente, ao longo do riacho do Medéia e córrego Luanda, os quais abastecem os açudes do Saco I e Cachoeira II, respectivamente.

Considerando os cálculos dos índices biofísicos relativos à imagem orbital do dia 28/09/2007, destacaram-se os valores do NDVI < 0,30, SAVI e EVI < 0,20, simulados na Figura 5 pelas cores amarelo e laranja, os quais indicam ausência de vegetação verde (caducifolia) em praticamente toda a área da unidade de conservação e sua zona de amortecimento, naquele período do ano, caracterizado como bastante seco. Este fato é confirmado pelo expressivo valor negativo obtido para o NDWI, principalmente ao norte e a oeste do PEMP, simulado pela cor vermelha (NDWI <-0,22), representando praticamente $50 \%$ da área da zona de amortecimento do parque.

A Figura 5 apresenta um comparativo entre os resultados obtidos para os índices referentes ao mês de setembro dos anos de 2007, 2013 e 2016. 


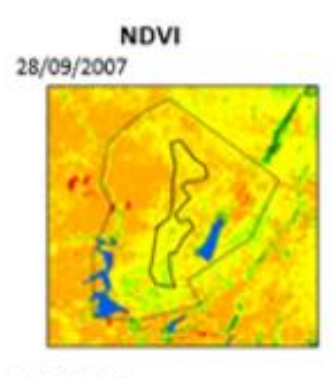

LAI

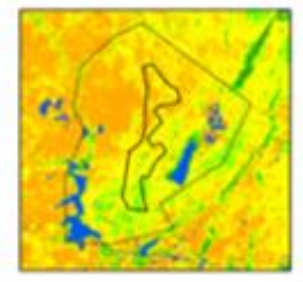

SAVI

EVI
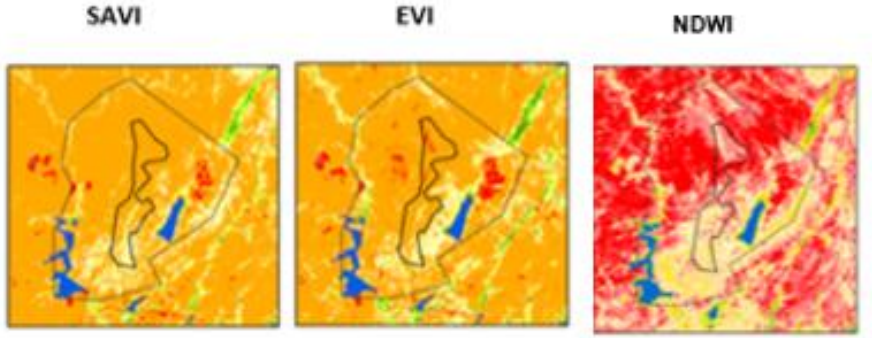

$28 / 09 / 2013$
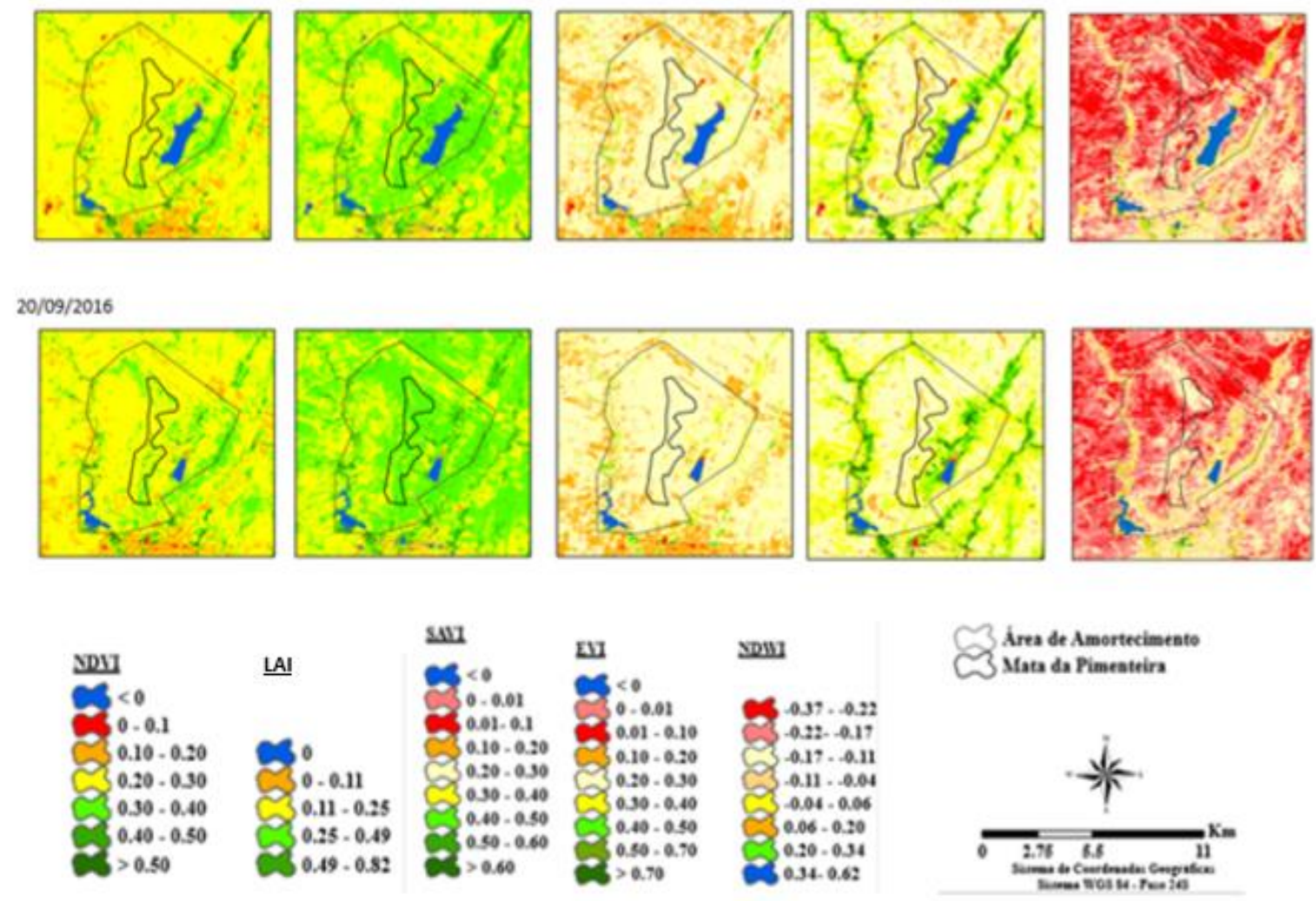

Figura 5 - Comparativo índices de vegetação do Parque Estadual Mata da Pimenteira (PEMP) para setembro de 2007, 2013 e 2016. Fonte: Bilar e Cerqueira (2017).

Nas imagens dos dias 28/09/2013 e 20/09/2016, o SAVI e o EVI apresentaram resultados muito semelhantes, na faixa de 0,20 a 0,30 , em quase todo o parque, indicando vegetação caducifólia e esparsa, além de áreas com solo exposto. Entretanto, chamaram a atenção os valores superiores a 0,40 , calculados para o EVI, simulados pelas tonalidades de cor verde, ao longo dos cursos de água que alimentam os açudes do Saco I e Cachoeira II. Os resultados dos cálculos para o NDWI nesses dois períodos revelaram que em setembro de 2016 o PEMP apresentou menor grau de estresse hídrico quando comparado a 2013, uma vez que mais de dois terços da área do parque atingiram a faixa de $-0,17$ a $-0,11$, simulada pela tonalidade de cor amarelo-claro.

Em relação ao índice de área foliar (LAI), em setembro de 2007 (Figura 5), predominaram na área do PEMP valores muito baixos, inferiores a 0,25 (cor amarelo), 
inclusive, cerca de dois terços da zona de amortecimento do parque apresentando valores < 0,11 (cor laranja) e menos de $10 \%$ na faixa superior a 0,25. Para os anos 2013 e 2016 os valores do LAI elevaram-se, atingindo a escala de 0,25 a 0,49 na maior parte do PEMP, simulados pela cor verde clara, com destaque para o ano 2016, onde mais de $85 \%$ da área do parque e $75 \%$ da porção leste de sua zona de amortecimento, no entorno do açude do Saco I, atingiram esse patamar.

A Figura 5 mostra que, em setembro de 2016, os valores de NDVI na faixa entre 0 e 0,10, simulado em vermelho, a sul e sudeste da ZA do PEMP aumentaram consideravelmente em relação ao mesmo período do ano de 2007.

\section{DISCUSSÃO}

A literatura confirma que a vegetação de caatinga mantém atividade fotossintética, mesmo durante o período de transição entre as estações chuvosa e seca, quando a vegetação ainda não está sob os efeitos do estresse hídrico acentuado (BILAR et al., 2016; MOURA et al., 2007; RIBEIRO, 2016; SILVA e ALMEIDA, 2013).

Os resultados obtidos corroboram os dados pluviométricos publicados pela National Oceanic and Atmospheric Administration - NOAA; do mesmo modo, confirmam dados de Molion e Bernardo (2002) sobre a tendência de escassez de chuvas em anos de El Niño, como em 2016, e a ocorrência do fenômeno contrário em anos de predominância de La Niña, como em 2007.

A série pluviométrica investigada por Silva e Almeida (2013), em 252 postos pluviométricos da rede hidrometereológica da antiga Superintendência de Desenvolvimento do Nordeste (SUDENE) e sete estações meteorológicas do Instituto Nacional de Meteorologia (INMET), para um período de pelo menos 30 anos, identificou que a média histórica anual da região na qual se localiza o PEMP é de, aproximadamente, $650 \mathrm{~mm}$. No entanto, os dados obtidos no Posto 12 IPA, em Serra Talhada-PE, localizado bem ao lado dessa unidade de conservação, e disponíveis no site da APAC, apontaram uma média pluviométrica mais elevada de, aproximadamente, $780 \mathrm{~mm}$ ao ano (média de 55 anos), ainda dentro do patamar típico do Semiárido nordestino, que é inferior a $800 \mathrm{~mm} \cdot \mathrm{ano}^{-1}$, de acordo com Moura et al. (2007). Tal fato pode ser explicado, dentre outros fatores, pela localização geográfica do PEMP, cuja área corresponde, em sua maior parte, a topos de serras com altitudes que variam entre 500 e 820 m, dados confirmados anteriormente por Silva e Almeida (2013), assim como pela maior presença de cobertura vegetal. 
Considerando os índices de vegetação calculados a partir de imagens orbitais captadas pelos sensores TM e OLI dos satélite Landsat 5 e 8, respectivamente, em períodos mais e menos chuvosos dos anos de 2007, 2013 e 2016, constatou-se que o regime pluviométrico exerce uma enorme influência sobre a vegetação do PEMP, ratificando Rodal e Sampaio (2002) acerca da caducifolia das plantas da Caatinga durante a estação sob elevado estresse hídrico, assim como seus impactos na fenologia de grande parte de suas espécies lenhosas, conforme Amorim, Sampaio e Araújo (2009) e Lima (2010).

Os valores calculados para o NDVI em todos os períodos investigados foram próximos aos de Ribeiro (2016) e Bezerra et al. (2014), relativos à aplicação desse índice para a avaliação da condição da cobertura vegetal na região semiárida do Nordeste brasileiro.

As respostas espectrais alcançadas pelo SAVI e pelo EVI evidenciaram suas capacidades de redução do efeito background e melhoramento do sinal das plantas, conforme Huete (1988) e Huete et al. (1997), especialmente para as imagens obtidas durante um período com escassez de chuvas.

Os resultados obtidos pelos três índices (NDVI, SAVI e EVI) se mostraram muito sensíveis ao regime pluviométrico e são eficazes para o aprimoramento da análise da condição da vegetação da unidade de conservação estudada, como proposto em estudos realizados em áreas de caatinga por Silva e Galvíncio (2012), Galvíncio et al. (2016) e Machado (2014).

Analisando-se a imagem do dia 26/07/2007 (Figura 4) verificou-se presença de caducifolia, característica das plantas do bioma Caatinga, diante da maior proximidade do período seco na região, fundamentalmente nas porções norte e oeste do PEMP e de sua zona de amortecimento, que apresentaram SAVI < 0,30. Esse fato fica mais notório ao se comparar essa imagem com a do dia 24/06/2013, logo após o período chuvoso, quando o resultado do SAVI para aquela mesma área foi justamente o oposto, atingindo valores superiores a 0,30.

O mecanismo de caducifolia, característico de muitas espécies da caatinga, em consequência de períodos com escassez hídrica prolongada, revela a grande resiliência, bem como a eficácia dos mecanismos de sobrevivência desta vegetação (CARRIÓN et al., 2017; GIULIETTI et al., 2004; LEAL, TABARELLI e SILVA, 2003; LIMA, 2010; SILVA, 2012). A ocorrência deste mecanismo é comum, após um período de escassez hídrica, em consequência do balanço hídrico da região, segundo pesquisas publicadas por Bilar et al. (2016), Ribeiro et al. (2016) e Silva e Almeida (2013).

Os resultados do LAI e do EVI inferiores a 0,20, simulados pelas cores marrom e laranja na Figura 4, respectivamente, na área imageada em julho de 2007, principalmente na 
porção noroeste da zona de amortecimento do PEMP, representam vegetação caducifólia e esparsa e solo exposto.

É importante ressaltar que, na área investigada, existem muitas propriedades rurais, em função de sua proximidade com o Córrego Luanda, que abastece o açude Cachoeira II, onde ainda é bastante comum a adoção de práticas agrícolas inadequadas como: a retirada da cobertura vegetal nativa e as queimadas, o que pode causar impactos negativos à vegetação do PEMP, requerendo uma maior atenção por parte dos órgãos públicos ambientais.

$\mathrm{Na}$ imagem do dia 24/06/2013 destacaram-se, na maior parte do PEMP, os valores do SAVI > 0,30 e LAI entre 0,60 e 0,80, simulados pelas tonalidades de cor verde na Figura 4, indicando que a vegetação apresenta boas condições fenológicas e está distribuída ao longo de grande parte da área do parque e nas porções leste e sudoeste de sua zona de amortecimento, nas proximidades dos corpos hídricos: açudes do Saco I e Cachoeira II respectivamente.

A eficiência na avaliação da condição fenológica da vegetação de caatinga através da aplicação do SAVI e LAI foi confirmada por Ribeiro (2016) e Ribeiro et al. (2016), ao obter LAI inferior a 1,0 para a maior parte das cenas nas proximidades da bacia hidrográfica do rio Pajeú, durante uma década (entre 2003 e 2013).

Nas imagens orbitais referentes aos meses de agosto de 2016 (Figura 4) e setembro dos anos de 2007, 2013 e 2016 (Figura 5) destacaram-se os baixos valores alcançados pelo NDVI, SAVI e EVI, inferiores a 0,30, indicando áreas secas com baixo regime pluviométrico.

A detecção de áreas com registros de baixo regime pluviométrico se mostrou eficiente através da determinação de valores de NDVI, SAVI e EVI inferiores a 0,30 e de valores negativos de NDWI, ratificando pesquisas realizadas por Barbosa, Hueti e Baethgen (2006); Gurgel, Ferreira e Luiz (2003); Novas et al. (2008), além dos estudos desenvolvidos por Oliveira et al. (2010) e Ribeiro (2016), em áreas típicas de vegetação de caatinga do Nordeste brasileiro. Por se tratar de região semiárida e, consequentemente, sob constante estresse hídrico, Bezerra, Silva e Bezerra (2011), Bezerra et al. (2014), Galvíncio et al. (2016), Oliveira et al. (2010), Silva e Galvíncio (2012) orientam a aplicação do NDWI para averiguar as alternâncias na umidade do solo, a susceptibilidade de desertificação em áreas degradas e a avaliação de corpos hídricos.

$\mathrm{O}$ aumento da área urbana de Serra Talhada, em bairros localizados às margens da BR 232 e da PE 365, ao sul e à sudeste da zona de amortecimento do PEMP, pode ser constatado ao se comparar as imagens do ano de setembro 2007 com aquelas do mesmo período do ano de 2016 (período de uma década), fundamentalmente, acompanhado a evolução espacial de 
áreas com valores de NDVI na faixa entre 0 e 0,10, simuladas em vermelho (Figura 5).

$\mathrm{O}$ crescimento da área urbanizada em Serra Talhada, especialmente nas margens da BR 232 e PE 365, nas proximidades da zona de amortecimento da PEMP, representa um risco para a manutenção da integridade da unidade de conservação estudada. Isto ocorre em função do incremento de atividades antrópicas potencialmente causadoras de impactos ambientais negativos. Segundo o IBGE (2017), a população estimada desse município, para 2017, totaliza 85.568 habitantes; o censo demográfico realizado em 2010 registrou 79.232 habitantes, portanto, crescendo cerca de 7,4\%, em apenas sete anos.

De uma forma geral, os resultados obtidos por todos os índices em setembro de 2016, no ápice do período de escassez hídrica na região estudada, indicaram uma melhor condição da vegetação do PEMP, em relação aos anos de 2013 e 2007, visto que atingiram patamares mais elevados (positivos) em suas respectivas escalas. Entretanto, registrou-se uma precipitação de 15,2 mm em 01/09/2016, portanto, 19 dias antes da captura da imagem orbital, ao passo que em setembro de 2013 não houve registro de precipitação e, em 2007, apenas $2 \mathrm{~mm}$ foram computados para esse mês. Isso indica que a vegetação do PEMP está relativamente bem preservada e com um adequado comportamento fenológico ao apresentar boa capacidade de recuperação como efeito da precipitação, conforme Rodrigues et al. (2009), segundo indicam os aumentos dos valores do LAI, em toda a área do parque e do EVI, ao longo dos cursos de água que alimentam os açudes Saco I e Cachoeira II, simulados e representados pelas tonalidades de cor verde na imagem (Figura 5).

\section{CONCLUSÕES}

A aplicação de índices da vegetação NDVI, LAI, SAVI, EVI e NDWI, obtidos através de imagens captadas remotamente pelos sensores TM e OLI dos satélites Landsat 5 e 8, mostrou-se eficaz para identificar a condição da cobertura vegetal do Parque Estadual Mata da Pimenteira, indicando sua distribuição espacial, riscos e o vigor da vegetação no período investigado, que considerou a transição entre as estações chuvosa e seca do semiárido.

A utilização conjunta desses parâmetros biofísicos proporcionou melhores resultados para esta investigação, considerando o seu caráter complementar. Os valores calculados para o NDVI foram ratificados pelas adequações e/ou melhoramentos promovidos pelo SAVI e pelo EVI e, quando associados aos resultados do LAI e do NDWI, mostraram que, de uma forma geral, a vegetação do PEMP se encontra relativamente bem preservada.

Os baixos valores obtidos pelos índices durante a estação seca mostraram que a porção 
noroeste da zona de amortecimento do PEMP apresentou maior patamar de estresse hídrico. Nessa área, utilizada há décadas para atividades agropecuárias, devido à sua proximidade do Córrego Luanda, curso de água que abastece o açude Cachoeira II, principal reservatório da região, existem, atualmente, comunidades e assentamentos rurais, que ainda sobrevivem, predominantemente, da agricultura e, em sua maioria, não fazem uso de técnicas agrícolas ambientalmente adequadas, o que gera riscos à vegetação do parque, demandando uma maior atenção por parte dos órgãos públicos ambientais.

O aumento da área urbana, ao sul e a sudeste da ZA do PEMP, às margens da BR $232 \mathrm{e}$ da PE 365, durante uma década (2007 a 2016), atestado pela evolução espaço-temporal das áreas com valores de NDVI entre 0 e 0,10 , também acarreta risco à vegetação do PEMP, por conta do incremento de atividades antrópicas potencialmente causadoras de impactos ambientais negativos.

As informações disponibilizadas por índices biofísicos de monitoramento ambiental podem e devem ser utilizadas para subsidiar a elaboração de novas políticas públicas, além da revisão de planos de manejo e outras decisões relacionadas ao dia a dia da gestão de unidades de conservação, como a identificação de áreas prioritárias para o desenvolvimento de ações de fiscalização, educação e compensação ambiental.

\section{AGRADECIMENTOS}

À Fundação de Amparo à Ciência e Tecnologia do Estado de Pernambuco (FACEPE), pela concessão de bolsa de estudos (nível doutorado) ao primeiro autor e ao Conselho Nacional de Desenvolvimento Científico e Tecnológico (CNPq), pela Bolsa de Produtividade concedida à segunda autora. À Agência Pernambucana de Meio Ambiente - CPRH. Ao Laboratório de Sensoriamento Remoto e Geoprocessamento do Departamento de Ciências Geográficas da Universidade Federal de Pernambuco - SERGEO/DCG/UFPE.

\section{REFERÊNCIAS}

AGÊNCIA PERNAMBUCANA DE ÁGUAS E CLIMA - APAC. Monitoramento pluviométrico de Serra Talhada, Posto 12 (IPA). Disponível em: http://www.apac.pe.gov.br/meteorologia/monitoramento-pluvio.php. Acesso em: 31 maio 2017.

ALLEN, R. G.; TASUMI, M.; TREZZA, R.; WATERS, R.; BASTIAANSSEN, W. SEBAL: surface energy balance algorithms for land. Idaho implementation, advanced training and users manual, version 1.0. Idaho: University of Idaho, 2002. 98p.

AMORIM, I. L.; SAMPAIO, E. V. S. B.; ARAÚJO, E. L. Fenologia de espécies lenhosas da caatinga do Seridó, RN. Revista Árvore, n. 33, p. 491-499, 2009.

BARBOSA, H. A.; HUETI, A. R.; BAETHGEN, W.E. A 20 - year study of NDVI variability 
over the Northeast Region of Brazil. Journal of Arid Environments, London, v. 67, p. 288307, 2006.

BENSUSAN, N. Conservação da biodiversidade em áreas protegidas. Rio de Janeiro: Editora FGV, 2006.

BEZERRA, J. M.; MOURA, G. B. A.; SILVA, G. B.; LOPES, P. M. O.; SILVA, E. F. F. Parâmetros biofísicos obtidos por sensoriamento remoto em região semiárida do estado do Rio Grande do Norte, Brasil. Revista Brasileira de Engenharia Agrícola e Ambiental, Campina Grande, v. 18, n. 1, p. 73-84, 2014. Disponível em: http://www.scielo.br/pdf/rbeaa/v18n1/v18n1a10.pdf. Acesso em: 31 maio 2017.

BEZERRA, M. V. C.; SILVA, B. B.; BEZERRA, B. B. Avaliação dos efeitos atmosféricos no albedo e NDVI obtidos com imagens de satélite. Revista Brasileira de Engenharia Agrícola e Ambiental, Campina Grande, v. 15, p. 709-717, 2011. Disponível em: http://www.scielo.br/pdf/rbeaa/v15n7/v15n07a09.pdf. Acesso em: 31 maio 2017.

BILAR, A. B. C. Localização do Parque Estadual Mata da Pimenteira. In: BILAR, A. B. C.; PIMENTEL, R. M. M.; ARAUJO, M. S. B. Sustentabilidade de assentamentos no entorno de unidades de conservação: o caso do Parque Estadual Mata da Pimenteira em Serra Talhada/PE. Sustentabilidade em debate. v. 7, Edição especial, 2016. p.195-211.

BILAR, A. B. C.; CARVAlHO, R. C. O.; GALVÍNCIO, J. D.; SOUZA, W. M. Climate changes and environmental migrations in the Northeastern Semiarid. Journal of Hyperspectral Remote Sensing, v. 6, n. 1, p. 36-43, 2016.

BRASIL. Lei ${ }^{\circ}$ 9.985, de 18 de julho de 2000. Institui o Sistema Nacional de Unidades de Conservação da Natureza. Diário Oficial da União. Brasília, 19 jul. 2000.

BRASIL. Ministério do Meio Ambiente. Bioma Caatinga. Disponível em: <http://www.mma.gov.br/biomas/caatinga>. Acesso em: 1 jun. 2017.

CARRIÓN, J. F., GASTAUER, M., MOTA, N. M., MEIRA-NETO, J. A. A. Facilitation as a driver of plant assemblages in Caatinga. Journal of Arid Environments, London, v. 142, p. 50-58, 2017.

CHAGAS, M. G. S. Condição biológica da vegetação em ecossistemas costeiros e do Sertão do Pajeú em Pernambuco. 2012. 123f. Tese (Doutorado) Programa de PósGraduação em Geografia da Universidade Federal de Pernambuco, Recife.

CURI, D. Gestão ambiental. São Paulo: Person Prentice Hall, 2011.

ESCOLA LATINO AMERICANA DE AREAS PROTEGIDAS - ELAP. Lições aprendidas sobre zoneamento em unidades de conservação e no seu entorno: comunidade de ensino e aprendizagem em planejamento de umidades de conservação. Brasília, WWF-Brasil, 2015.

FARIAS, S. G. G. DE. Estrutura e funcionamento da comunidade vegetal em uma área de caatinga em Serra Talhada - PE. 2013. 117f. Tese (Doutorado). Universidade Federal Rural de Pernambuco, Programa de Pós-Graduação em Ciências Florestais, Recife.

FERRAZ, E. M. N.; RODAL, M. J. N.; SAMPAIO, E. V. S. B., PEREIRA, R. C. A. Composição florística em trechos de vegetação de caatinga e brejo de altitude na região do Vale do Pajeú, Pernambuco. Revista Brasileira de Botânica, São Paulo, v. 21, n. 1, p. 7-15, 1998.

FERREIRA, E. G. B. S. Potencial fisiológico de sementes e produção de mudas de espécies florestais ocorrentes na Caatinga de Pernambuco. 2013. 159f. Tese (Doutorado). Universidade Federal Rural de Pernambuco, Programa de Pós-Graduação em Ciências Florestais, Recife.

FLORENZANO, T. G. Iniciação ao sensoriamento remoto. São Paulo: Oficina de textos, 2007. 101p.

GALVÍNCIO, J. D.; PEREIRA, J. A. S.; FRANÇA, L. M. A.; LINS, T. M. P. Análise da variação da vegetação dos períodos secos e chuvosos através do SAVI e albedo de superfície no município de Belo Jardim - PE. Revista Rede Eletrônica do PRODEMA - REDE, 
Fortaleza, v. 10, n. 2, p. 133-146, jul./2016.

GAO, B. C. NDWI - A normalized difference water index for remote sensing of vegetation liquid water from space. Remote Sensing of Environment, v. 58, p. 257-266, 1996.

GIULIETTI, A. M.; BOCAGE NETA, A. N.; CASTRO, A. A. J. F.; GAMARRA-ROJAS, C. F. L.; SAMPAIO, E. V. S. B.; VIRGINIO, J. F.; QUEIROZ, L. P.; FIGUEIREDO, M. A.; RODAL, M. J. N.; BARBOSA, M. R. V.; HARLEY, R. M. Diagnóstico da vegetação nativa do bioma Caatinga. In: SILVA, J. M. C.; TABARELLI, M.; FONSECA, M. T.; LINS, L. V. (Orgs.). Biodiversidade da Caatinga: áreas e ações prioritárias para a conservação. Brasília: Ministério do Meio Ambiente, 2004. pp. 48-90.

GOMES, L. F. A. M.; GOMES, C. F. S.; ALMEIDA, A. T. Tomada de decisão gerencial: enfoque multicritério. 3. ed. São Paulo: Atlas, 2009.

GURGEL, H.C.; FERREIRA, N.J.; LUIZ, A.J.B. Estudo da variabilidade do NDVI sobre o Brasil utilizando-se a análise de agrupamento. Revista Brasileira de Engenharia Agrícola e Ambiental, Campina Grande, v. 7, n. 1, p. 85-90, 2003.

HUETE, A. R. A Soil-Adjusted Vegetation Index (SAVI). Remote Sensing of Environment, v. 25, p. 295-309, 1988.

HUETE, A. R.; LUI, H. Q.; BATCHILY, K.; VAN LEEUWEN, W. A Comparison of Vegetation Indices over a Global Set of TM Images for EOS-MODIS. Remote Sensing of Environment, n. 59, p. 440-451, 1997.

INSTITUTO BRASILEIRO DE GEOGRAFIA E ESTATÍSTICA - IBGE. Cidades. Pernambuco - Serra Talhada. Disponível em: http://cidades.ibge.gov.br/xtras/perfil.php?codmun=261390. Acesso em: 4 nov. 2017.

LEAL, I. R.; TABARELli, M.; SILVA, J. M. C. (Eds). Ecologia e Conservação da Caatinga. Editora Universitária da UFPE, Recife, 2003. 822p.

LIMA, A. L. A. Tipos funcionais fenológicos em espécies lenhosas da Caatinga, Nordeste do Brasil. 2010. 116f. Tese (Doutorado). Programa de Pós-Graduação em Botânica, Universidade Federal Rural de Pernambuco, Recife.

LIMA, A. L. A.; MELO; MELO, A. L.; MENEZES, T. G. C.; FARIAS, S. G. G.; LIMA, L. R.; SAMPAIO, E. V. S. B.; RODAL, M. J. N. Estrutura e funcionamento de vegetação lenhosa. In: SANTOS, E. M.; MELO JÚNIOR, M.; CAVALCANTI, J. S. S.; ALEIDA, G. V. L. (Orgs.) Parque estadual Mata da Pimenteira: riqueza natural e conservação da caatinga. Recife: UFRPE, 2013. Cap. 7, pp. 105-120.

MACHADO, C. C. C. Alterações na superfície do Parque Nacional do Catimbau (PEBrasil): consolidação dos aspectos biofísicos na definição dos indicadores ambientais do bioma Caatinga. 2014. 221f. Tese (Doutorado) Programa de Pós-Graduação em Ciência Geográficas, Universidade Federal de Pernambuco, Recife.

MATOS, S. S.; MELO, A. L.; SILVA, J. S. Mimosoideae no Parque Estadual Mata da Pimenteira, Serra Talhada, Pernambuco. Anais... LXVII Congresso Nacional de Botânica. Vitória-ES, Sociedade Botânica do Brasil - SBB, 2016.

MENESES, P. R. Princípios de sensoriamento remoto. In: MENESES, P. R.; ALMEIDA, T. (Orgs.) Introdução ao processamento de imagens de sensoriamento remoto. Brasília: UNB, 2012. Cap. 1, pp. 1-31.

MENEZES, T. G. C. Diversidade florística, dinâmica temporal de herbáceas e aspectos morfofuncionais de plântulas de espécies lenhosas em área de caatinga, Serra Talhada, Pernambuco. 2011. Monografia (Conclusão de curso). Universidade Federal Rural de Pernambuco, Unidade Acadêmica de Serra Talhada, Curso de Bacharelado em Ciências Biológicas.

MOLION, L. C. B.; BERNARDO, S. O. Uma Revisão da Dinâmica das Chuvas no Nordeste Brasileiro. Revista Brasileira de Meteorologia, v. 17, n. 1, p. 1-10, 2002.

MOREIRA, M. A. Fundamentos do sensoriamento remoto e metodologias de aplicação. 
2.ed. Viçosa - MG: UFV, 2003. 307p.

MOURA, M. S. B.; GALVÍNCIO, J. D.; BRITTO, L. T. L.; SOUZA, L. S. B.; SA, I. I. S.; SILVA, T. G. F. Clima e água de chuva no semiárido. In: BRITO, L. T. L., MOURA, M. S. B.; GAMA, G. F. B. (Orgs.) Potencialidade de água de chuva no semiárido brasileiro. Petrolina: EMBRAPA/Semiárido, 2007. pp. 37-59.

NATIONAL OCEANIC AND ATMOSPHERIC ADMINISTRATION - NOAA. Oceanic Niño Index - ONI. El Niño and La Niña Years and Intensities. Washington, D. C. Updated May 2017. Disponível em: http://ggweather.com/enso/oni.htm. Acesso em: 1 jun. 2017.

NOBRE, P. Mudanças climáticas e desertificação: os desafios para o Estado Brasileiro. In: LIMA, R. C. C.; CAVALCANTE, A. M. B.; PEREZ-MARIN, A. M. (Eds). Desertificação e mudanças climáticas no semiárido brasileiro. Campina Grande: INSA-PB, 2011. 209p.

NOVAS, M. F. B.; CRUZ, P. P. N.; SILVA, R.; DI PACE, F. T. Análise da variação dos índices de vegetação estimados por sensoriamento remoto em dois períodos ao sul da bacia do rio Traipu-AL. II Simpósio Brasileiro de Ciências Geodésicas e Tecnologia da Geoinformação. Anais... Recife: Universidade Federal de Pernambuco, 2008.

NOVO, E. M. L. M. Sensoriamento remoto: princípios e aplicações. São Paulo: Blücher, 2008. 388p.

OLIVEIRA, J. S. S. Índices de vegetação (NDVI, IVAS, IAF, NDWI) como subsídio à gestão do uso e ocupação do solo na zona de amortecimento da Reserva Biológica de Saltinho, Pernambuco. 91f., 2013. Dissertação (Mestrado). Programa de Pós-Graduação em Geografia, Universidade Federal de Pernambuco, Recife, 2013.

OLIVEIRA, T. H.; SILVA, J. S.; MACHADO, C. C. C.; GALVÍNCIO, J. D.; NÓBREGA, R. S.; PIMENTEL, R. M. M. Detecção espaço-temporal de estresse hídrico na vegetação do semiárido no nordeste do Brasil utilizando NDVI e NDWI - Estudo de caso Serra da Capivara e Serra do Congo - PI. In: VI Seminário Latino Americano de Geografia Física, 2010, Coimbra. Disponível em: http://www.uc.pt/fluc/cegot/VISLAGF/actas/tema2/tiago. Acesso em: 2 jun. 2017.

PERNAMBUCO. Decreto ${ }^{\circ} 37.823$, de 30 de janeiro de 2012. Cria o Parque Estadual Mata da Pimenteira, localizado no Município de Serra Talhada/PE. Diário Oficial de Pernambuco, Recife, 31 jan. 2012.

Parque Estadual Mata da Pimenteira: Plano de manejo. Secretaria de Meio Ambiente e Sustentabilidade, Agência Estadual de Meio Ambiente. Recife, PE, 2013. 90p.

PINTO, L. P. Unidades de conservação. Revista Diversa UFMG. Belo Horizonte, ano 7, n.14, jul. 2008. Disponível em: https://www.ufmg.br/diversa/14/index.php/unidade-deconservacao/unidades-de-conservacao.html. Acesso em: 11 out. 2016.

QUEIROZ, L. P. Distribuição das espécies de Leguminoseae na caatinga. In: SAMPAIO, E. V. S. B.; GIULIETTI, A. M.; VIRGÍNIO, J.; GAMARRA-ROJAS, C. F. L. (Eds.). Vegetação e flora das caatingas. Recife: Associação de Plantas do Nordeste e Centro Nordestino de Informações sobre Plantas, 2002, pp. 141-153.

RIBEIRO, E. P.; NOBREGA, R. S.; MOTA FILHO, F. de O.; MOREIRA, E. B. M. Estimativa dos índices de vegetação na detecção de mudanças ambientais na bacia hidrográfica do rio Pajeú. Revista Geosul. Florianópolis, v. 31, n. 62, p. 59-92, jul./ago, 2016. RIBEIRO, E. P. Mudanças climáticas e desertificação na Bacia Hidrográfica do Rio Pajeú. 2016. 178f. Tese (Doutorado). Programa de Pós-Graduação em Geografia. Universidade Federal de Pernambuco. Recife.

RODAL, M. J. N.; SAMPAIO, E. V. S. B. A. Vegetação do Bioma Caatinga. In: SAMPAIO, E. V. S. B.; GIULIETTI, A. M.; VIRGÍNIO, J.; GAMARRA-ROJAS, C. F. L. (Eds.). Vegetação e flora das caatingas. Recife: Associação de Plantas do Nordeste e Centro Nordestino de Informações sobre Plantas, 2002, pp. 11-24. 
RODRIGUES, E. L.; FERNANDES, D. H. F.; ELMIRO, M. A. T.; FARIA, S. D. Avaliação da cobertura vegetal por meio dos índices de vegetação SR, NDVI, SAVI e EVI na sub-bacia do Vale do Rio Itapecerica, Alto São Francisco, em Minas Gerais. XVI Simpósio Brasileiro de Sensoriamento Remoto. Anais... Foz do Iguaçu-PR: Instituto Nacional de Pesquisas Espaciais - INPE, 2013.

RODRIGUES, J. O.; ANDRADE, E. M.; TEIXEIRA, A. S.; SILVA, B. B. Sazonalidade de variáveis biofísicas em regiões semiáridas pelo emprego do sensoriamento remoto. Engenharia Agrícola, Jaboticabal, v. 29, n. 3, p. 452-465, jul./set. 2009.

RODRIGUEZ, J. M. M.; SILVA, E. V.; CAVALCANTI, A. P. B. Geoecologia das paisagens: uma visão geossistêmica da análise ambiental. 4. ed. Fortaleza: Edições UCF, 2013.

ROUSE, J. W.; HAAS, R. H.; SCHELL, J. A.; DEERING, D. W. Monitoring vegetation systems in the great plains with ERTS. In: Earth Resources Technology Satellite - 1 Symposium, 3, 1973. Proceedings. Washington, 1973, v. 1, Sec. A, pp. 309-317.

SALLO, F. S.; FRANÇA, M. S.; MORAIS, D. M.; RODRIGUES, R.; BIUDES, M. S. Estimativa de componentes do balanço de radiação em diferentes tipos de uso e cobertura do solo. Revista Ambiente \& Água, Taubaté, v. 9, n. 2, p. 347-358, abr./jun. 2014.

SEIFFERT, M. E. B. Gestão ambiental: instrumentos, esferas de ação e educação ambiental. São Paulo: Atlas, 2010. 310p.

SHIMIZU, T. Decisão nas organizações. 2. ed. São Paulo: Atlas, 2006. 415p.

SILVA, M.D. DA; FERREIRA, C.P.; PINTO, J.A.B.; PIMENTEL, R.M.M. 2008. Tipos Funcionais Vegetais em um Fragmento Sombreado de Mata Atlântica, Pernambuco. Revista de Geografia, v. 25, n. 03, p. 06-19.

SILVA, T. G. F.; ALMEIDA, A. Q. Climatologia e características geomorfológicas. In: SANTOS, E. M.; MELO JÚNIOR, M.; CAVALCANTI, J. S. S.; ALEIDA, G. V. L. (Orgs.) Parque estadual Mata da Pimenteira: riqueza natural e conservação da caatinga. Recife: UFRPE, 2013. Cap. 2, pp. 27-36.

SILVA, L. G.; GALVÍNCIO, J. D. Análise comparativa da variação nos índices NDVI e SAVI no Sítio PELD - 22, em Petrolina - PE, na primeira década do século XXI. Revista Brasileira de Geografia Física, n. 06, p. 1446-1456, 2012.

SILVA, M. D. Resiliência e susceptibilidade de tipos funcionais vegetais na paisagem no semiárido nordestino. 2012. 121f. Recife. Tese (Doutorado). Programa de Pós-Graduação em Geografia da Universidade Federal de Pernambuco, Recife.

TEIXEIRA, R. F. B. Índice de vegetação IVDN a partir do NOAA e do Terascan na Funceme. Boletim da Sociedade Brasileira de Meteorologia. v. 27, n. 01, p. 12-18, 2003.

WENG, Q. Remote Sensing and GIS Integration: Theories, Methods, and Applications. New York: McGraw-Hill, 2010. 397p.

Recebido em 29 de março de 2018.

Aceito em 23 de abril de 2018. 